\section{Update on}

\section{Cuneyt Evren ${ }^{1 \oplus}$, Muge Bozkurt ${ }^{\oplus}$}

\section{Methamphetamine: an Old Problem that We have Recently Encountered}

'Bakirkoy Training and Research Hospital for Psychiatry Neurology and Neurosurgery, Research, Treatment and Training Center for Alcohol and Substance Dependence (AMATEM), Istanbul - Turkey

How to cite this article: Evren C, Bozkurt M. Update on methamphetamine: an old problem that we have recently encountered. Dusunen Adam The Journal of Psychiatry and Neurological Sciences 2018;31:1-10. https://doi.org/10.5350/DAJPN20183101001

Methamphetamine is a substance chemically closely related to amphetamine with a greater potential for harm due to its greater potency and longer half-life (1). Among illicit stimulant drugs (cocaine, amphetamine, methamphetamine and 3,4-Methylenedioxymethamphetamine), amphetamine has always been the more common one in Europe, but recent data show that the methamphetamine market is on the rise (2). Acute and long-term use of methamphetamine are associated with cardiovascular, pulmonary, neurological, and mental health problems, ranging from anxiety, aggression, and depression to acute paranoid psychosis. In addition, injecting the drug is a risk factor for infectious diseases (2). Methamphetamine seems to be more dangerous than other stimulants due to its acute complications, long-term neurotoxicity, and high potential for dependence. The European Monitoring Centre for Drugs and Drug Addiction (EMCDDA) considers the harm to public health caused by methamphetamine to be significant, even at low prevalence rates, due to its severe negative effects ( 3 ).

\section{History of Methamphetamine Use}

Methamphetamine was first synthesized in Japan during the $19^{\text {th }}$ century, but it gained popularity during the Second World War among soldiers who were given amphetamine or methamphetamine to stay awake for long periods of time. In the years after the war, methamphetamine became widely available for the treatment of a range of disorders including narcolepsy, depression, obesity, alcohol dependency, and attention deficit hyperactivity disorder (ADHD). As it has an appetite-decreasing effect, it was also marketed to women for weight loss $(3,4)$. As the therapeutic use of the substance spread, its abuse also increased. Between 1945 and 1955, the first methamphetamine epidemics were documented in the United States of America (USA) (5) and Japan (6). The spread of nonmedical use of methamphetamine among the general public in these countries in the following years has been largely attributed to stockpiles of pills left over from the war. 
Concerns about the availability and use of methamphetamine have been growing for some time. Historically, the use of methamphetamine has been confined largely to the Czech Republic and Slovakia, but reports of increasing methamphetamine use coming out of different countries have raised interest. These reports include the use of methamphetamine among heroin injectors in Greece, an increasing use of crystal methamphetamine in Germany, evidence from drug seizures and forensic examinations indicating a market change from amphetamine to methamphetamine in some Nordic countries, and concerns about methamphetamine injection among groups of gay men in the United Kingdom (3).

\section{Epidemiology and Availability of Methamphetamine}

Over 12 million people in the USA (4.7\% of total responders) have used methamphetamine in their lifetimes; 1.2 million people $(0.4 \%)$ reported using methamphetamine in the past year, and approximately $440,000(0.2 \%)$ of those identified as users over the past month (7). In Europe, only two countries have provided recent estimates of the number of problematic methamphetamine users, with estimates for adults (15-64 years) of around $0.42 \%$ for the Czech Republic and about $0.21 \%$ in Slovakia (2). In Turkey, a general estimate of methamphetamine users is not known, but a regional study revealed that the amphetamine/ methamphetamine group has been the most commonly used substance group in the last two years according to laboratory screening results for illicit drugs (8). An increase in the number of patients reporting methamphetamine use was also seen in clinical settings.

Importantly, the market for methamphetamine appears to be expanding in terms of locations of manufacture and trafficking routes as well as in terms of demand (2). Between 2006 and 2011, the number of methamphetamine seizures reported to the EMCDDA nearly tripled, while the quantities of seized methamphetamine increased six fold. The largest quantities of methamphetamine were seized in Turkey, followed by Norway, Lithuania, Sweden, and Latvia. Turkey first reported seizing methamphetamine in 2009, following the emergence of Iran as a producer and the use of Turkey as a transit country for the export of the drug to the Asia-Pacific region (3). There are particularly worrying signs from Greece, Cyprus, and Turkey where, for the first time in Europe, crystal methamphetamine smoking is identified as an emerging threat, with the possibility of spreading among vulnerable populations $(2,3)$. In recent years, methamphetamine seizures in the Czech Republic and Germany have also been on the rise (3).

\section{Risk Groups for Methamphetamine Use}

Young age, low educational level, and the use of other psychoactive substances are associated with an increased risk of methamphetamine abuse (1). Methamphetamine abuse also seems to be prevalent in specific populations such as groups of gay men, mainly in London, who participate in so-called 'slamming' or 'chem-sex' parties. Sexual intercourse under the influence of drugs is associated with an intravenous use of the drug, where the injecting equipment is often shared, and the use of a cocktail of drugs like mephedrone and gamma-hydroxybutyrate (GHB) $(9,10)$. Although the extent of this type of drug use remains unclear, drug services in London have reported increasing demand for treatment linked to problems associated with methamphetamine use by gay men (3). Iranian studies revealed that in 2015 2016, methamphetamine use in patients under methadone treatment reached up to $60.3 \%$ among men (11) and $89.5 \%$ among women (12). These results suggest that patients with opioid-use disorder under agonist treatment (or not) were another at-risk population for methamphetamine use (13).

\section{Chemistry of Methamphetamine}

Methamphetamine, also known as metamfetamine, $\mathrm{N}$-methylamphetamine, methylamphetamine, and desoxyephedrine, is a psychostimulant of the phenethylamine and amphetamine class of 
psychoactive drugs. Methamphetamine exists in two stereoisomers. D-methamphetamine (the dextrorotatory enantiomer) is a more powerful psychostimulant with 3-5 times the central nervous system (CNS) activity, and its effects last longer compared to L-methamphetamine or the levorotatory enantiomer (14). At high doses, the L-enantiomer is reported to produce an intoxication similar to that caused by the D-enantiomer, but its psychoactive effects are relatively short and less desired (15). Illicit methamphetamine encountered in Europe is normally found to be a mixture of the D- and L-enantiomers in equal proportions, known in chemistry as a racemic mixture (3). Methamphetamine can be taken orally or nasally; in addition, injection is common among highrisk users in some countries. Smoking crystal methamphetamine is also prevalent in Australia, the USA, and Southeast Asia $(2,3,16)$.

Pseudoephedrine and ephedrine are popular precursors for methamphetamine production because of their ready availability as an over-the-counter medication (17). Production based on ephedrine and pseudoephedrine is an easy one-step method mainly used in Central Europe (Czech Republic, Germany, Poland, Slovakia) (3). Another precursor, 1-phenyl-2propanone (benzyl methyl ketone, BMK), is used especially in Lithuania, China, and Russia (3). Restriction of sales of pseudoephedrine and ephedrine in some countries has led to new ways of producing these substances from precursors such as phenylacetylcarbinol (3).

Synthetic processes that use pseudoephedrine as a precursor yield a free-base, volatile form of methamphetamine, which is not marketable due to its high volatility. The addition of hydrochloric acid precipitates methamphetamine into a usable 'base' form, which is a damp powder or crystal (18). It can be swallowed, snorted, injected, or smoked. Partygoers often prefer the route of smoking or snorting.

Methamphetamine powder or "speed" is more likely to contain adulterants and tends to be of lower purity than the crystal form of the drug. Its color can range from white to brown to orange, yellow or pink, depending on the reagents used in the manufacturing process. Powder methamphetamine is smoked, snorted, or dissolved and injected (18). The powder form found on the illicit drugs market is similar to powder amphetamine in purity and appearance, and the two are often indistinguishable for both dealers and users (3).

Large white or translucent crystals of methamphetamine hydrochloride, called "ice" or "crystalline meth," are derived from recrystallizing base methamphetamine, which can be complicated and requires specialized equipment and expertise. It is predominantly smoked or injected in some regions $(3,18)$. Compared to the lower purity forms, crystalline methamphetamine is associated with an increased incidence of dependence (19). In order to make methamphetamine more affordable, powdered methamphetamine is sometimes mixed with other adulterants and compressed into pills. In order to smoke the substance, the tablets are crushed and heated and the fumes are then inhaled (18). Users of base methamphetamine and ice are described as more "hard core," more aggressive, more chaotic, and exhibit more social problems. They also experience more rapid physical decline than users of methamphetamine powder and pills $(20,21)$.

\section{Pharmacology of Methamphetamine}

Methamphetamine can readily cross the bloodbrain barrier and rapidly penetrate into the brain (22). It stimulates the release and partially blocks the reuptake of synthesized catecholamines in the central nervous system (CNS). As its chemical structure is similar to that of monoamines, it is recognized as a substrate for the dopamine transporter (DAT), noradrenaline transporter (NET), serotonin transporter (SERT), and vesicular monoamine transporter-2 (VMAT-2) and reverses their endogenous function, thereby redistributing monoamines from storage vesicles into the cytosol (23). It also attenuates the metabolism of monoamines by inhibiting monoamine oxidase (24). The net result of methamphetamine is an overstimulation of the monoaminergic pathways in the central and peripheral nervous system that can lead to severe dysfunction or even neuronal degeneration 
in several brain areas, including the striatum, prefrontal cortex, and hippocampus (25).

Peripheral release of monoamine neurotransmitters mediates its acute effects including euphoria, enhanced mental acuity, positive mood, and social and sexual disinhibition, as well as systemic sympathomimetic effects $(23,26)$. The wide distribution of monoamines throughout the CNS, interactions between the monoamine pathways, baseline dopamine functioning, and peripherally mediated effects of methamphetamine add to the complexity of methamphetamine's effect on the monoamine systems (23).

Increased dopamine release may largely account for the abuse potential of methamphetamine (27), but its effect on the endogenous opioid system may also mediate some rewarding properties (17) because opioid receptors and peptides are highly expressed in brain areas involved in reward and motivation, such as the ventral tegmental area (VTA) and nucleus accumbens (28). Methamphetamine effects on the dopaminergic, noradrenergic, serotonergic, and opioidergic neurotransmitter systems mediate the behavioral and cognitive changes after its use (17).

\section{Pharmacokinetics of Methamphetamine}

Smoking and intravenous injection of methamphetamine result in a near-immediate euphoric sensation, which lasts for several minutes. After intranasal and oral administration, it takes approximately 5 and 20 minutes respectively to reach peak euphoric state, and the effect is reported to last for 8 to 12 hours (29). The drug is largely metabolized in the liver and then excreted by the kidneys. The majority of methamphetamine is excreted unchanged as methamphetamine, followed by 4-hydroxymethamphetamine and amphetamine. Approximately $70 \%$ of a single oral dose is excreted in the urine within 24 hours (30). With repeated dosing, methamphetamine can be detected for a longer time, up to 7 days (31). Based on the pharmacokinetic data, the typical assessment of methamphetamine in clinical studies consists of urinalysis at 3-4 day intervals (i.e., twice weekly) (17).

\section{Effects of Methamphetamine}

The repeated release of monoamines in the CNS is responsible for several neurological and psychiatric problems in methamphetamine users. There is clear evidence for a dose-dependent effect (32), with higher doses of methamphetamine resulting in more severe and deleterious consequences brought on by the disruption of these pathways. Excessive dopaminergic function leads to psychotic symptoms while deregulation of glutamatergic, GABAergic, cholinergic, and opioidergic signaling contributes to other symptoms including aggression, depression, motor impairments, and sleep disruption (33).

Short-term effects of methamphetamine include euphoria, alertness, wakefulness, increased confidence, hyperactivity, and loss of appetite $(33,34)$. Dopamine release is responsible for the euphoric effects of methamphetamine, but long-term use of methamphetamine causes molecular changes in the dopamine system, contributing to nerve terminal damage in the brain and leading to impaired motor skills, rapid cognitive decline, increased anxiety, psychotic disorders, violent behavior, hallucination, delusions and depression (35). Due to these changes in the CNS, the acute euphorigenic effects of methamphetamine usually transform into psychiatric conditions during binge use. Higher doses of methamphetamine will cause aggressiveness, restlessness, repetitive behavior, agitation, confusion, anxiety, irritability, dysphoria, violent behavior, psychomotor impairment, stereotypy, auditory hallucinations, panic, and paranoia $(36,37)$. During the end stage of a methamphetamine binge, euphoria is replaced by negative symptoms (e.g., anxiety, feelings of emptiness) and the appearance of most of the symptoms described above (33).

Beyond psychiatric symptoms, physiological symptoms like loss of appetite, increased heart rate, blood pressure, and breathing rate as well as dilation of the pupils and raised body temperature, sweating, headache, blurred vision, dizziness, stomach cramps, muscle fatigue and cramps, chest pain and shaking, dehydration, nausea and vomiting (38), hyperthermia, 
hypertension, cardiac arrhythmia, seizures, cerebral hemorrhage, ischemic infarct, renal failure, rhabdomyolysis, and coma or death can also result from methamphetamine use $(33,39,40)$.

\section{Withdrawal of Methamphetamine}

The withdrawal period of methamphetamine is subjectively highly distressing but not a life-threatening condition. The abstinence syndrome is variable with regard to intensity and duration. Depression, fatigue, hypersomnia, and increased appetite, irritability, anxiety, aggression, and intense cravings for methamphetamine are common symptoms (29). Depressive symptoms are the hallmark of methamphetamine withdrawal, lasting beyond two weeks of abstinence $(41,42)$. In this period, depression and anxiety may also lead to suicidal thoughts (33). Craving has been observed to last for at least 5 weeks, while users have been found particularly vulnerable to relapse during days 7 to 14 of abstinence (42).

\section{Methamphetamine Psychosis}

Six to $46 \%$ of methamphetamine users have been estimated to develop methamphetamine-associated psychosis (43), which is frequently characterized by persecutory delusions and auditory and visual hallucinations, delusions of reference and thought broadcasting (43). While psychosis occurring during a binge episode or withdrawal is usually transient, the susceptibility to psychotic disorders increases with chronic methamphetamine use (44). According to the International Classification of Diseases (ICD-10) (45) and Diagnostic and Statistical Manual of Mental Disorders (DSM-5) (46), a psychotic disorder is not diagnosed when the observed symptoms are consistent with the expected effects of intoxication or withdrawal from methamphetamine. Therefore, cases with transient psychotic symptoms do not constitute a diagnosable psychotic disorder. However, these patients may still require pharmacological management when their state is accompanied by acute agitation, violent behavior, or otherwise severe distress and impairment in functioning (47). Generally, the psychotic state can be resolved with dopamine receptor antagonists (43). The DSM-5 (46) defines substance-induced psychosis as that preceding the onset of substance use or persisting for less than one month after acute substance withdrawal or intoxication. However, some patients with methamphetamine psychosis do not remit psychotic symptoms for weeks or months, exhibiting the so-called "prolonged type of methamphetamineinduced psychosis" (44). A rigid 1-month cut-off may not be applicable in cases of methamphetamine-related psychosis that might be longer in duration, yet not appropriate for a diagnosis of schizophrenia-spectrum disorder (47).

A follow-up study in Thailand revealed that onequarter of patients with methamphetamine psychosis had been given the diagnosis of schizophrenia within the 5 years following their first hospitalization (48). Close monitoring for the development of chronic or recurrent psychosis among individuals with transient symptoms, possible pharmacological management of acute symptoms, and behavioral treatment and psychoeducation addressing methamphetamine use and its association with psychosis are needed.

\section{Neurotoxicity and Cognitive Functions}

Through its actions on the dopaminergic, noradrenergic, serotonergic, and opioidergic systems, repeated use of methamphetamine is associated with significant neurotoxic effects and neurocognitive deficits (17). The mechanisms responsible for methamphetamine neurotoxicity are complicated and may include excessive dopamine level in the cytosol and synaptic cleft, oxidative stress, neuroinflammation, and pro-apoptotic changes (49).

A meta-analysis of 44 studies concluded that methamphetamine users have moderate impairment across most cognitive domains, including attention, executive functions, language/verbal fluency, verbal learning and memory, visual memory, and working memory. Deficits in impulsivity/reward processing and social cognition were also prominent, whereas 
visual learning and visuo-spatial abilities were relatively spared cognitive domains (50). Authors also reported that the effects of methamphetamine on social cognition and impulsivity/reward processing were based on a small number of studies, and as such, these results need to be replicated (50). Functional and structural neuroimaging studies have indicated that cognitive impairments are accompanied by neurochemical, functional, and morphological changes in particular brain regions including the striatum, prefrontal cortex, and hippocampus (49). Individual differences in variables such as age, education level, and genotype appear to moderate the relationship between methamphetamine use and cognitive deficits (51). These impairments are generally observed during the first three months of abstinence, with some impairments improving following protracted sustained abstinence (52).

\section{Other Health Risks Associated with Methamphetamine Use}

Reports of methamphetamine users emphasize problems associated with depression, suicidal behavior, violence, psychosis, poor physical health, and emaciation (3,26). Depression and suicidal ideation can be observed during active drug use, withdrawal period, and even in the abstinence period $(53,54)$. Mood transients and impulsive behavior seem to be a component of methamphetamine-related psychiatric syndromes, with the most severe outcome lying in an increase in suicidality (55). High levels of accidents and suicides are also reported in high-risk users of methamphetamine compared with the general population (3).

Although the injection of drugs is generally on the decline across Europe, high levels of sexual risk-taking behaviors among users of methamphetamines may contribute to an increased risk of contracting human immunodeficiency virus (HIV) and other sexually transmitted infections (20). Experts are also reporting poor adherence to HIV medication and increased rates of hepatitis $C$ virus reinfection among gay men participating in slamming parties (3).

\section{Acute Treatment for Methamphetamine Intoxication}

Methamphetamine intoxication should be treated in a quiet environment isolated from outside stimuli. Given that other substances might have been consumed as well, the administration of medication should be performed cautiously. If the patient needs treatment for marked agitation, aggressiveness, or psychotic symptoms, benzodiazepines should be used as the agent of first choice. If benzodiazepines are not sufficient to sedate the patient, adding an antipsychotic drug may be considered, especially if the patient has delusions or hallucinations (9). Patients with methamphetamine-use disorder should be offered a course of qualified withdrawal treatment for a minimum of three weeks, and acute treatment may also be combined with the use of other psychotherapeutic methods, such as behavioral therapy or contingency management as soon as possible (9).

\section{Pharmacotherapy for Methamphetamine Use Disorder}

There are no approved medications for treating methamphetamine-use disorder, and pharmacotherapy is recommended as an adjunct to psychosocial interventions rather than being a primary component of treatment (56). The drugs studied for methamphetamine-use disorder include acetylcysteine, antidepressants, antiepileptic drugs, atypical antipsychotic drugs, calcium antagonists, muscle relaxants, opioid antagonists, psychostimulants, and varenicline (9). Methamphetamine-related persistent or comorbid syndromes such as methamphetamineassociated psychosis, depressive syndromes, anxiety, and sleep disorders are usually treated in a symptomoriented manner (57).

Unlike opiate treatment with opiate analogues, dopamine-analogue treatment has not yet produced convincing results (57). A recent systematic review found no effect of psychostimulant agents on sustained abstinence or retention in treatment (58). Novel 
approaches for the treatment of methamphetamineuse disorder include neuroimmune modulators (minocycline, ibudilast), cognitive enhancers (rivastigmine, galantamine, atomoxetine, modafinil, citicoline), vaccines, and oxytocin (59).

\section{Psychotherapeutic Interventions for Methamphetamine Use Disorder}

Any person who uses methamphetamine, with or without a diagnosis of methamphetamine-use disorder, should be offered psychotherapeutic counseling or treatment of an appropriate type for his or her individual needs and motivation (9). Cognitive behavioral approaches, be they in conjunction with pharmacotherapy or not, have been shown to increase treatment attendance and to reduce methamphetamine use and risky sexual behavior (60-62). Contingency management has also been associated with better retention in treatment, lower rates of methamphetamine use, and longer periods of sustained abstinence over the course of the treatment experience (63). On the other hand, methamphetamine-related cognitive deficits in executive functioning, particularly those related to inhibitory control, have been hypothesized to potentially render heavily cognitive-based treatments ineffective (64).

Beyond contingency management and cognitive behavioral therapy, guidelines also reported that psychoeducation, motivational interviewing, motivation enhancement, acceptance and commitment therapy, Matrix model (cognitive behavioral therapy with family education and selfhelp participation) and FAST (Family Alternative Treatment Activities, Self-Help and Therapeutic Community), stepped-care approaches (a need-based, incremental system of interventions, ranging from low-threshold educative approaches to complex inpatient treatment methods) and community-based treatments were efficient approaches for methamphetamine-use disorder (9). It is recommended that patients be offered at least one full year of further follow-up care to prevent relapse (9).

\section{Further Interventions for Methamphetamine Use Disorder}

Evidence suggests that physical exercise is effective in reducing anxiety and depression and improving fitness and quality of life in previous methamphetamine users. Overall, including exercise might significantly enhance recovery in previous methamphetamine dependents; thus, exercise therapy should be offered and provided as supportive treatment (65). In a randomized controlled trial, neurofeedback was also found to improve addictionspecific endpoints and quality of life compared to pharmacotherapy alone (66).

Harm-reduction interventions can be recommended for patients who do not want to achieve total abstinence, or are not able to do so, including reducing consumption, abstaining from intravenous consumption, avoiding dangerous drug interactions (such as serotonin syndrome), regular nutrition, proper attention to dental health and hygiene, and safe sex (9). Distributing gelatine capsules for oral administration of the drug to injecting methamphetamine users in order to reduce injection-related harm or provision of smoking equipment or safer-smoking kits through needle and syringe programs have also been tried in order to achieve harm reduction $(3,67)$.

\section{Conclusion and Future Interventions}

The increasing abuse of methamphetamine in many countries has resulted in a growing demand to treat patients who have acquired a methamphetaminerelated disorder. Even at a relatively low prevalence, methamphetamine has the potential to cause significant harm, and addiction care is not the only area that needs to adapt to this burden. There is a need for multi-disciplinary drug-help facilities as well as for first-aid deliverers and hospital staff and guidelines for methamphetamine-related disorders (9). Interventions against methamphetamine use are also needed and have to be tailored according to individual countries. Knowledge available on the use of methamphetamine and related problems and interventions for prevention 
remains incomplete. Future research systematically addressing these gaps is needed to provide a roadmap for effective treatment and prevention programs for methamphetamine-use disorder. Studies should be

\section{REFERENCES}

1. de Matos EG, Hannemann TV, Atzendorf J, Kraus L, Piontek D. The consumption of new psychoactive substances and methamphetamine. Dtsch Arztebl Int 2018; 115:49-55.

2. United Nations Office on Drugs and Crime (UNODC). World Drug Report 2012. United Nations; Vienna: 2013.

3. European Monitoring Centre for Drugs and Drug Addiction. Exploring methamphetamine trends in Europe, EMCDDA Papers, Publications Office of the European Union, Luxembourg, 2014. http://www.emcdda.europa.eu/system/ files/publications/787/TDAU14001ENN_460800.pdf (Last accessed on 13 March 2018)

4. Vearrier D, Greenberg MI, Miller SN, Okaneku JT, Haggerty DA. Methamphetamine: history, pathophysiology, adverse health effects, current trends, and hazards associated with the clandestine manufacture of methamphetamine. Dis Mon 2012; 58:38-89. [CrossRef]

5. Shrem MT, Halkitis PN. Methamphetamine abuse in the United States: contextual, psychological and sociological considerations. J Health Psychol 2008; 13:669-679. [CrossRef]

6. Ahmad K. Asia grapples with spreading amphetamine abuse. Lancet 2003; 361:1878-1879. [CrossRef]

7. Substance Abuse and Mental Health Services Administration (SAMHSA). Results from the 2012 National Survey on Drug Use and Health: Summary of National Findings, NSDUH Series H-46, HHS Publication No. (SMA) 13-4795. Substance Abuse and Mental Health Services Administration; Rockville, MD: 2013

8. Karakukcu C, Ciraci MZ, Kocer D, Erturk-Zararsiz G, Reyhancan M, Altintop I. Regional drug abuse prevalence depending on laboratory based urine illicit drug screening results. Anadolu Psikiyatri Derg 2018; 19:169-176. [CrossRef]

9. Gouzoulis-Mayfrank E, Härtel-Petri R, Hamdorf W, HavemannReinecke U, Mühlig S, Wodarz N. Methamphetamine-related disorders. Dtsch Arztebl Int 2017; 114:455-641.

10. Kirby T, Thornber-Dunwell M. High-risk drug practices tighten grip on London gay scene. Lancet 2013; 381:101-102. [CrossRef]

11. Radfar SR, Mohsenifar S, Noroozi A. Integration of methamphetamine harm reduction into opioid harm reduction services in Iran: preliminary results of a pilot study. Iran J Psychiatry Behav Sci 2017; 11:e7730. [CrossRef] performed to identify the dimensions of methamphetamine use in Turkey, and addiction treatment centers should be prepared for this approaching danger.

12. Massah $\mathrm{O}$, Moradi A. The prevalence of methamphetamine dependence among Iranian women in methadone maintenance therapy in Tehran, Iran. Iranian Journal of Psychiatry 2018; 13:10-14.

13. Alammehrjerdi Z, Ezard N, Dolan K. Methamphetamine dependence in methadone treatment services in Iran: the first literature review of a new health concern. Asian J Psychiatr 2018; 31:49-55. [CrossRef]

14. Ciccarone D. Stimulant abuse: pharmacology, cocaine, methamphetamine, treatment, attempts at pharmacotherapy. Prim Care 2011; 38:41-58. [CrossRef]

15. Mendelson J, Uemura N, Harris D, Nath RP, Fernandez E, Jacob P 3rd, Everhart ET, Jones RT. Human pharmacology of the methamphetamine stereoisomers. Clin Pharmacol Ther 2006; 80:403-420. [CrossRef]

16. United Nations Office on Drugs and Crime (UNODC). World Drug Report 2013. United Nations; Vienna: 2013.

17. Courtney KE, Ray LA. Methamphetamine: an update on epidemiology, pharmacology, clinical phenomenology, and treatment literature. Drug Alcohol Depend 2014; 143:11-21. [CrossRef]

18. Chomchai C, Chomchai S. Global patterns of methamphetamine use. Curr Opin Psychiatry 2015; 28:269-274. [CrossRef]

19. McKetin R, Kozel N, Douglas J, Ali R, Vicknasingam B, Lund J, Li JH. The rise of methamphetamine in Southeast and East Asia. Drug Alcohol Rev 2008; 27:220-228. [CrossRef]

20. Degenhardt L, Roxburgh A, Black E, Bruno R, Campbell G, Kinner S, Fetherston J. The epidemiology of methamphetamine use and harm in Australia. Drug Alcohol Rev 2008; 27:243-252.

[CrossRef]

21. Topp L, Degenhardt L, Kaye S, Darke S. The emergence of potent forms of methamphetamine in Sydney, Australia: a case study of the IDRS as a strategic early warning system. Drug Alcohol Rev 2002; 21:341-348. [CrossRef]

22. Nordahl TE, Salo R, Leamon M. Neuropsychological effects of chronic methamphetamine use on neurotransmitters and cognition: a review. J Neuropsychiatry Clin Neurosci 2003; 15:317-325. [CrossRef] 
23. Cruickshank CC, Dyer KR. A review of the clinical pharmacology of methamphetamine. Addiction 2009; 104:1085-1099. [CrossRef]

24. Sulzer D, Sonders MS, Poulsen NW, Galli A. Mechanisms of neurotransmitter release by amphetamines: a review. Prog Neurobiol 2005; 75:406-433. [CrossRef]

25. Yamamoto BK, Moszczynska A, Gudelsky GA. Amphetamine toxicities: classical and emerging mechanisms. Ann N Y Acad Sci 2010; 1187:101-121. [CrossRef]

26. Darke S, Kaye S, McKetin R, Duflou J. Major physical and psychological harms of methamphetamine use. Drug Alcohol Rev 2008; 27:253-262. [CrossRef]

27. Baumann MH, Ayestas MA, Sharpe LG, Lewis DB, Rice KC, Rothman RB. Persistent antagonism of methamphetamineinduced dopamine release in rats pretreated with GBR12909 decanoate. J Pharmacol Exp Ther 2002; 301:1190-1197. [CrossRef]

28. Mansour A, Fox CA, Akil H, Watson SJ. Opioid-receptor mRNA expression in the rat CNS: anatomical and functional implications. Trends Neurosci 1995; 18:22-29. [CrossRef]

29. Meredith CW, Jaffe C, Ang-Lee K, Saxon AJ. Implications of chronic methamphetamine use: a literature review. Harv Rev Psychiatry 2005; 13:141-154. [CrossRef]

30. Kim I, Oyler JM, Moolchan ET, Cone EJ, Huestis MA. Urinary pharmacokinetics of methamphetamine and its metabolite, amphetamine following controlled oral administration to humans. Ther Drug Monit 2004; 26:664-672. [CrossRef]

31. Oyler JM, Cone EJ, Joseph RE Jr, Moolchan ET, Huestis MA. Duration of detectable methamphetamine and amphetamine excretion in urine after controlled oral administration of methamphetamine to humans. Clin Chem 2002; 48:1703-1714.

32. Wallace TL, Gudelsky GA, Vorhees CV. Methamphetamineinduced neurotoxicity alters locomotor activity, stereotypic behavior, and stimulated dopamine release in the rat. J Neurosci 1999; 19:9141-9148.

33. Moszczynska A, Callan SP. Molecular, behavioral, and physiological consequences of methamphetamine neurotoxicity: implications for treatment. J Pharmacol Exp Ther 2017; 362:474488. [CrossRef]

34. Pike E, Stoops WW, Rush CR. Acute buspirone dosing enhances abuse-related subjective effects of oral methamphetamine. Pharmacol Biochem Behav 2016; 150-151:87-93. [CrossRef]

35. Rusyniak DE. Neurologic manifestations of chronic methamphetamine abuse. Neurol Clin 2011; 29:641-655. [CrossRef]
36. Hart CL, Gunderson EW, Perez A, Kirkpatrick MG, Thurmond A, Comer SD, Foltin RW. Acute physiological and behavioral effects of intranasal methamphetamine in humans. Neuropsychopharmacology 2008; 33:1847-1855. [CrossRef]

37. Zweben JE, Cohen JB, Christian D, Galloway GP, Salinardi M, Parent D, Iguchi M; Methamphetamine Treatment Project. Psychiatric symptoms in methamphetamine users. Am J Addict 2004; 13:181-190. [CrossRef]

38. Harro J. Neuropsychiatric adverse effects of amphetamine and methamphetamine. Int Rev Neurobiol 2015; 120:179-204.

[CrossRef]

39. Richards JR, Bretz SW, Johnson EB, Turnipseed SD, Brofeldt BT, Derlet RW. Methamphetamine abuse and emergency department utilization. West J Med 1999; 170:198-202.

40. Richards JR, Johnson EB, Stark RW, Derlet RW. Methamphetamine abuse and rhabdomyolysis in the ED: a 5-year study. Am J Emerg Med 1999; 17:681-685. [CrossRef]

41. Newton TF, Kalechstein AD, Duran S, Vansluis N, Ling W. Methamphetamine abstinence syndrome: preliminary findings. Am J Addict 2004; 13:248-255. [CrossRef]

42. Zorick T, Nestor L, Miotto K, Sugar C, Hellemann G, Scanlon G, Rawson R, London ED. Withdrawal symptoms in abstinent methamphetamine-dependent subjects. Addiction 2010; 105:1809-1818. [CrossRef]

43. Grant KM, LeVan TD, Wells SM, Li M, Stoltenberg SF, Gendelman HE, Carlo G, Bevins RA. Methamphetamineassociated psychosis. J Neuroimmune Pharmacol 2012; 7:113139. [CrossRef]

44. Ujike $\mathrm{H}$, Sato M. Clinical features of sensitization to methamphetamine observed in patients with methamphetamine dependence and psychosis. Ann N Y Acad Sci 2004; 1025:279287. [CrossRef]

45. World Health Organization. The ICD-10 Classification of Mental and Behavioral Disorders. Diagnostic Criteria For Research; Geneva: 1992.

46. American Psychiatric Association. Diagnostic and statistical manual of mental disorders. 5. Arlington, VA: American Psychiatric Publishing; 2013.

47. Glasner-Edwards S, Mooney LJ. Methamphetamine psychosis: epidemiology and management. CNS Drugs 2014; 28:11151126. [CrossRef]

48. Kittirattanapaiboon P, Mahatnirunkul S, Booncharoen H, Thummawomg P, Dumrongchai U, Chutha W. Longterm outcomes in methamphetamine psychosis after first hospitalization. Drug Alcohol Rev 2010; 29:456-461.

\section{[CrossRef]}


49. Shin EJ, Dang DK, Tran TV, Tran HQ, Jeong JH, Nah SY, Jang CG, Yamada K, Nabeshima T, Kim HC. Current understanding of methamphetamine-associated dopaminergic neurodegeneration and psychotoxic behaviors. Arch Pharm Res 2017; 40:403-428. [CrossRef]

50. Potvin S, Pelletier J, Grot S, Hébert C, Barr AM, Lecomte T. Cognitive deficits in individuals with methamphetamine use disorder: a meta-analysis. Addict Behav 2018; 80:154-160. [CrossRef]

51. Dean AC, Groman SM, Morales AM, London ED. An evaluation of the evidence that methamphetamine abuse causes cognitive decline in humans. Neuropsychopharmacology 2013; 38:259274. [CrossRef]

52. Iudicello JE, Woods SP, Vigil O, Scott JC, Cherner M, Heaton RK, Atkinson JH, Grant I; HIV Neurobehavioral Research Center (HNRC) Group. Longer term improvement invneurocognitive functioning and affective distress among methamphetamine users who achieve stable abstinence. J Clin Exp Neuropsychol 2010; 32:704-718. [CrossRef]

53. Kalechstein AD, Newton TF, Longshore D, Anglin MD, van Gorp WG, Gawin FH. Psychiatric comorbidity of methamphetamine dependence in a forensic sample. J Neuropsychiatry Clin Neurosci 2000; 12:480-484. [CrossRef]

54. Scott JC, Woods SP, Matt GE, Meyer RA, Heaton RK, Atkinson JH, Grant I. Neurocognitive effects of methamphetamine: a critical review and meta-analysis. Neuropsychol Rev 2007; 17:275-297. [CrossRef]

55. Glasner-Edwards S, Mooney LJ, Marinelli-Casey P, Hillhouse M, Ang A, Rawson R; Methamphetamine Treatment Project. Risk factors for suicide attempts in methamphetamine-dependent patients. Am J Addict 2008; 17:24-27. [CrossRef]

56. Karila L, Weinstein A, Aubin HJ, Benyamina A, Reynaud M, Batki SL. Pharmacological approaches to methamphetamine dependence: a focused review. Br J Clin Pharmacol 2010; 69:578-592. [CrossRef]

57. Härtel-Petri R, Krampe-Scheidler A, Braunwarth WD, Havemann-Reinecke $U$, Jeschke P, Looser W, Mühlig S, Schäfer I, Scherbaum N, Bothe L, Schaefer C, Hamdorf W. Evidence-based guidelines for the pharmacologic management of methamphetamine dependence, relapse prevention, chronic methamphetamine-related, and comorbid psychiatric disorders in post-acute settings. Pharmacopsychiatry 2017; 50:96-104.

\section{[CrossRef]}

58. Bhatt M, Zielinski L, Baker-Beal L, Bhatnagar N, Mouravska N, Laplante P, Worster A, Thabane L, Samaan Z. Efficacy and safety of psychostimulants for amphetamine and methamphetamine use disorders: a systematic review and meta-analysis. Syst Rev 2016; 5:189. [CrossRef]

59. Ballester J, Valentine G, Sofuoglu M. Pharmacological treatments for methamphetamine addiction: current status and future directions. Expert Rev Clin Pharmacol 2017; 10:305-314.

60. Lee NK, Rawson RA. A systematic review of cognitive and behavioural therapies for methamphetamine dependence. Drug Alcohol Rev 2008; 27:309-317. [CrossRef]

61. McElhiney MC, Rabkin JG, Rabkin R, Nunes EV. Provigil (modafinil) plus cognitive behavioral therapy for methamphetamine use in HIV+ gay men: a pilot study. Am J Drug Alcohol Abuse 2009; 35:34-37. [CrossRef]

62. Reback CJ, Shoptaw S. Development of an evidence-based gay-specific cognitive behavioral therapy intervention for methamphetamine-abusing gay and bisexual men. Addict Behav 2014; 39:1286-1291. [CrossRef]

63. Roll JM, Chudzynski J, Cameron JM, Howell DN, McPherson S. Duration effects in contingency management treatment of methamphetamine disorders. Addict Behav 2013; 38:24552462. [CrossRef]

64. Baicy K, London ED. Corticolimbic dysregulation and chronic methamphetamine abuse. Addiction 2007; 102(Suppl 1):5-15.

\section{[CrossRef]}

65. Morris L, Stander J, Ebrahim W, Eksteen S, Meaden OA, Ras A, Wessels A. Effect of exercise versus cognitive behavioural therapy or no intervention on anxiety, depression, fitness and quality of life in adults with previous methamphetamine dependency: a systematic review. Addict Sci Clin Pract 2018; 13:4. [CrossRef]

66. Rostami R, Dehghani-Arani F. Neurofeedback training as a new method in treatment of crystal methamphetamine dependent patients: a preliminary study. Appl Psychophysiol Biofeedback 2015; 40:151-161. [CrossRef]

67. Mravcik V, Skarupova K, Orlikova B, Zabransky T, Karachaliou $\mathrm{K}$, Schulte B. Use of gelatine capsules for application of methamphetamine: a new harm reduction approach. Int J Drug Policy 2011; 22:172-173. [CrossRef] 